\title{
EL CONTROL DE LA REAL ACADEMIA DE BELLAS ARTES DE SAN FERNANDO SOBRE LA ARQUITECTURA GADITANA
}

\section{MARÍA DOLORES ANTIGÜEDAD DEL CASTILLO-OLIVARES}

UNIVERSIDAD NACIONAL DE EDUCACIÓN A DISTANCIA

ORCID iD: 0000-0003-0532-2511

\begin{abstract}
RESUMEN
El trabajo pretende aportar nuevos datos para el estudio de la arquitectura gaditana desde el inicio de la renovación a finales del siglo XVIII hasta mediados del siglo XIX momento de consolidación de la Arquitectura Isabelina. Partiendo de los trabajos de especialistas reconocidos, se aporta documentación muy precisa del Archivo de la Real Academia de Bellas Artes de San Fernando sobre la formación de los arquitectos, su ejercicio profesional y el control y censura que la Comisión de Arquitectura ejerció sobre los arquitectos gaditanos y en especial sobre Torcuato José Benjumeda y Juan Daura.
\end{abstract}

\section{PALABRAS CLAVE}

Arquitectura, Real Academia Bellas Artes de San Fernando, Cádiz, barroco, Neoclasicismo, Eclecticismo, Torcuato Benjumeda, Juan Daura.

\section{THE CONTROL OF THE ROYAL ACADEMY OF FINE ARTS OF SAN FERNANDO ON GADITAN ARCHITECTURE}

\begin{abstract}
The work aims to provide new data for the study of Cadiz architecture from the beginning of the renovation at the end of the 18th century until the middle of the 19th century, the moment of consolidation of Elizabethan Architecture. Based on the work of recognized specialists, very precise documentation is provided from the Archive of the Royal Academy of Fine Arts of San Fernando on the training of architects, their professional practice and the control and censorship that the Architecture Commission exercised on Cadiz architects and especially about Torcuato José Benjumeda and Juan Daura.
\end{abstract}

\section{KEYWORDS}

Architecture, Royal Academy of Fine Arts of San Fernando, Cádiz, Baroque, Neoclassicisme, Eclecticism, Torcuato Benjumeda, Juan Daura. 


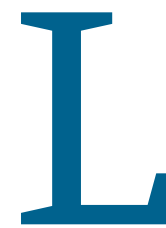

a arquitectura barroca en España dio muestras, según avanzaba el siglo XVIII, de agotamiento y búsqueda de un nuevo ideal que a finales de la centuria desembocaría en la consecución de un verdadero estilo, un resurgimiento o restablecimiento de las artes o Neoclasicismo ${ }^{1}$. El siglo XIX llevó a la escena urbana nuevos modelos de embellecimiento arquitectónico del agrado de la burguesía que como clase ascendente quiso identificarse con un modelo de ciudad alejada de las realizaciones del Antiguo Régimen.

La ciudad de Cádiz vivió un momento de esplendor en el siglo XVIII con el establecimiento de la Casa de Contratación en 1717, con anterioridad asentada en Sevilla, y por el consiguiente monopolio del comercio con América. A fines de siglo esa pujanza económica entrará en declive y la ciudad acogerá a una burguesía comercial acaudalada que conferirá un aspecto renovado a su arquitectura a la vez que impulsará el crecimiento extramuros de la ciudad ${ }^{2}$.

Desde mediados de siglo la arquitectura gaditana y la enseñanza de la arquitectura, al igual que en el resto de España, estuvo sometida al control de la Real Academia de Bellas Artes de San Fernando hasta el establecimiento de la Escuela de Arquitectura, creada por Real Decreto el 25 de septiembre de 1844 que en 1857 será el centro oficial para la formación de los arquitectos.

La Real Academia de Bellas Artes de San Fernando fue creada el 13 de junio de 1752 reinando Fernando VI (1713-1759) aunque sus primeros antecedentes están en el reinado de su padre Felipe V. Siguiendo su modelo se formarán las academias provinciales en las principales ciudades del país. La Real Academia Provincial de Bellas Artes de Cádiz inició sus actividades en 1777 como Escuela de Nobles Artes de Cádiz y desde 1778 fue Academia delegada de la madrileña de San Fernando. En 1842 se convertirá en Academia Nacional con competencias en la educación artística y responsable de los informes técnicos ${ }^{3}$.

A la muerte de Fernando VI, su hermano Carlos III ocupó el trono de España el 13 de julio de 1760 hasta su fallecimiento el 14 de diciembre de 1788. Sus años de gobierno supusieron la

\footnotetext{
1 HONOUR, Hugh. Neoclasicismo. Madrid: Ed. Xarait, 1882. p. 104. El autor insiste en que el término Neoclasicismo es una denominación moderna que alude a la recreación del Clasicismo por su carácter de "revival" de estilos pasados. 2 CIRICI NARVÁEZ, Juan Ramón. Arquitectura Isabelina en Cádiz. 1833-1868. Cádiz: Excmo. Ayuntamiento de Cádiz, 1982. P. 44 y sS.

3 CIRICI NARVÁEZ, Juan Ramón. La Academia Gaditana de Bellas Artes, policía de la buena arquitectura. Cincuenta años de informes facultativos. 1835-1885. Trocadero. No 6-7, 1994-1995. p. 337.
} 
incorporación del país a las corrientes de la Ilustración secundadas por el trabajo de ilustrados españoles como Pedro Rodríguez Campomanes (1723-1802), Pedro Abarca de Bolea, X conde de Aranda (1719-1798) y José Moñino y Redondo, I conde de Floridablanca (17281808). En el campo de las artes y de la arquitectura se impuso el gusto clásico internacional en detrimento del barroco ornamental y castizo. A finales del siglo XVIII los contactos con el exterior y los viajes de arquitectos y artistas para conocer los restos de la Antigüedad pondrán de moda el Neoclasicismo.

Con Carlos llegaron a la corte madrileña arquitectos y artistas que como Francisco Sabatini (Palermo 1721- Madrid 1797) habían estado a su servicio cuando ocupaba el trono de Nápoles y Sicilia como Carlos VII. Sabatini fue desde 1760 maestro mayor de las obras reales, más tarde también teniente general del cuerpo de Ingenieros. La relevancia de su figura en la Corte prevaleció sobre la de arquitectos que como Ventura Rodríguez Tizón (1717-1785) discípulo de Filippo Juvarra (1678-1736) se habían formado en las obras reales. Ventura Rodríguez fue Director General de Arquitectura de la Academia de San Fernando entre 1766 y 1775, su orientación facilitó la superación de los modelos del barroco romano y la asimilación de las lecciones aprendidas en las excavaciones de Herculano y Pompeya que había financiado el mismo Carlos III ${ }^{4}$.

El Monarca desde los inicios de su reinado encomendó a la Academia el control de la práctica arquitectónica para acabar con el estilo caprichoso del último barroco y conseguir una arquitectura institucional sencilla y funcional que bebiera de las fuentes clásicas. Para esa tarea contó con la colaboración de figuras como Antonio Ponz Piquer (1725-1792) que como ferviente antibarroco, difundió estos principios desde la Academia de la que fue secretario hasta 1790.

Sendos decretos de 23 y 25 de noviembre de 1777 dispusieron que ni el Consejo de Castilla, ni los Arzobispos, Obispos o prelados de las órdenes regulares pudieran construir obra alguna sagrada o profana sin que sus diseños no hubieran sido examinados y censurados por la Academia. Con respecto a las obras públicas el rey mandó el 11 de octubre de 1779 que ni el Consejo de Arquitectura, ni sus escribanías diesen curso a diseños que no hubieran sido aprobados por ella y no llevaran la firma del secretario de la Academia. Una Real Orden de 28 de febrero

4 Francisco Sabatini había delineado en 1750 los templos griegos de Paestum lo que no supuso una especial devoción por las ruinas tan de moda en esos momentos frente a Ventura Rodríguez que nunca visitó Italia. RODRÍGUEZ RUIZ, Delfín. La arquitectura pulcra de Francisco Sabatini. VV.AA. Francisco Sabatini (1721-1797). La arquitectura como metáfora del poder. Madrid: Ed. Electa, 1993. pp.23-49. 
de 1787 confirmó a todos los Magistrados y cabildos del reino las disposiciones de 1777 con la prohibición de construir sin la aprobación de la Academia de San Fernando o la de San Carlos de Valencia. En 1800 se envió una circular a los Académicos de Mérito y supernumerarios, así como a los arquitectos para que remitiesen los planos de las obras públicas que se les encargasen, disposiciones que continuaron vigentes en 1818, tras la Guerra de la Independencia 5 .

El control de la Academia sobre la arquitectura comenzaba por la formación de los arquitectos que debería estar alejada de las enseñanzas impartidas por los Gremios o las Órdenes Regulares. Se trató de implementar un sistema de enseñanza en donde los diferentes niveles y oficios propios de la arquitectura estuvieran sujetos a controles con la obligación de superar exámenes que asegurasen que se poseía la cualificación necesaria para realizar las labores propias de la profesión. Una Real Cédula de 22 de marzo de 1786 firmada por el conde de Floridablanca creó la Comisión de Arquitectura que sería responsable de las pruebas para conseguir los títulos de maestros de obra o arquitectos ${ }^{6}$. La Comisión con su elevada cualificación técnica, pretendía el control de la construcción en el reino porque obligaba a que "se vean, se examinen y forme dictamen sobre los proyectos de obras públicas" siguiendo criterios que no estaban tan claros en los planes de enseñanza de la arquitectura donde no existía un modelo común ni siquiera un modelo académico único 7 .

En Cádiz desde 1788 la Escuela de Nobles Artes primero, desde 1842 Academia Provincial, siempre bajo el control de la Academia de San Fernando, ejerció una vigilancia efectiva sobre las artes en la provincia, controlando el trabajo de arquitectos, maestros de obras y artistas. Su cometido no se refería sólo a aspectos formales y estilísticos, sino la denuncia, consulta y aprobación de nuevas obras, la conservación de las existentes y la vigilancia del patrimonio monumental histórico y artístico ${ }^{8}$.

5 Archivo Real Academia Bellas Artes de San Fernando (desde ahora ARABASF): Leg. 25-2/2. Resumen de disposiciones hasta 1818, firmado por Narciso Pascual y Colomer.

6 GARCÍA MELERO, José Enrique. Arquitectura y burocracia: el proceso del proyecto en la Comisión de Arquitectura de la Academia (1786-1808). Espacio, Tiempo y Forma. UNED, Historia del Arte, tomo 4, 1991. p. 283-348. El autor describe minuciosamente el proceso de censura de proyectos y las variantes de examen para acceder a arquitecto o a Académico de Mérito.

7 RODRÍGUEZ RUIZ, Delfín. Arquitectura y ciudad. VV.AA. Carlos III y la Ilustración. Madrid: Ministerio de Cultura, Vol. I, 1988. p.331. El autor mantiene que durante el reinado de Carlos III la arquitectura española no emprendió un camino coherente hacia el neoclasicismo, sino que fue escenario de un debate entre el barroco nacional, el clasicismo, el barroco clasicista y el orden de los ingenieros, que desde la Academia pretendió impulsar un clasicismo amparado en los grandes modelos renacentistas y barrocos.

8 CIRICI NARVÉZ, Juan Ramón. La Academia Gaditana de Bellas Artes, policía de la buena arquitectura. Cincuenta años de informes facultativos.1835-1885. Trocadero. Revista de Historia Moderna y Contemporánea. Cádiz, Facultad de Filosofía y Letras, Universidad de Cádiz. No 6-7, 1994-1995. pp.335 y ss. 
En abril de 1808 el secretario de la Academia José Munarriz solicitó al Secretario de la Comisión de Arquitectura, Silvestre Pérez, la relación de maestros de obras y arquitectos aprobados por dicha Comisión o por las Academias de San Carlos de Valencia, San Luis de Zaragoza o la Purísima Concepción de Valladolid. La relación que se adjunta como respuesta recoge los datos puestos al día hasta 1804 en la que aparecen como Académicos de Mérito establecidos en Cádiz, Miguel Olivares y Guerrero y Torcuato Josef de Benjumeda, Bartolomé de Ojea Matamoros en el Puerto de Santa María y Josef de Bargas y Sánchez aprobado como maestro de obras?.

Hasta esa fecha la nómina de arquitectos en Cádiz es más amplia aunque nos vamos a ceñir a sus figuras principales con el fin de entender la evolución de la arquitectura gaditana desde la segunda mitad del siglo XVIII hasta el Eclecticismo.

Una figura singular es D. Gaspar Molina y Zaldívar, III marqués de Ureña y IV conde de Saucedilla (1741-1806) que en 1757 con sólo dieciséis años es nombrado académico de honor y de mérito por la pintura ${ }^{10}$. El marqués de Ureña poseyó un perfil rico en sus diversas facetas como pintor, músico, viajero, científico, escritor y sobre todo diletante; en todas sus actividades fue el ejemplo del hombre ilustrado. Ureña tuvo responsabilidades en la construcción de la población militar de San Carlos en la Isla del León cuyos primeros proyectos se debieron a Francisco Sabatini, con quien colaboró hasta la decisiva participación del ingeniero militar y marino Vicente Imperial Digueri (1745-1816) que es quien le proporcionará el diseño definitivo ${ }^{1}$. En 1789 fue nombrado intendente y director de obra, continuó la obra de Imperial e inició la construcción del Observatorio Astronómico en 1793 siguiendo las ideas del ilustre militar Joseph de Mazarredo, Teniente General de la Real Armada (1745-1812) ${ }^{12}$. El marqués de Ureña, tal y como dejó escrito, aportó a la arquitectura la superación del barroco clasicista al seguir las lecciones que proporcionaba la arquitectura de los antiguos Griegos y Romanos o los clásicos españoles como Ontañón, Alonso de Covarrubias, Siloe o

9 ARABASF: Leg. 25-2/2. Arquitectos Directores, tenientes Directores, Académicos de mérito y supernumerarios de la real Academia de San Fernando con todas las facultades del Arte: año 1804.

10 ARABASF: Cargos y títulos académicos (1752-2019). En la relación aparece como Garpar Molina Rocha, un error ya que éste era el nombre de su tío, religioso agustino y obispo de Almería personaje de enorme influencia que justificaría que a edad temprana fuera aceptado como académico; aunque no fue merecedor de ningún premio de pintura sí superó los exámenes. Https://rah.es/biografias/20448/gaspar-molina-y-rocha. Consultado el 6/11/2020.

11 TORREJÓN CHAVES, Juan. "Vicente Ignacio Imperial Digueri y Trejo: ingeniero militar, marino, urbanista y arquitecto del siglo XVIII". Espacio, Tiempo y Forma, serie VII Historia del Arte, tomo 2, 1989. p.308 y ss.

12 SAMBRICIO, Carlos: 1991. Territorio y ciudad en la España de la Ilustración. Madrid, Ministerio de Obras Públicas y Transportes, Instituto del Territorio y Urbanismo, p. 503. 
Antonio de Arfe. En su pensamiento estaba el deseo de regresar a la sencillez, simplicidad y lógica de la cabaña primitiva, origen de la arquitectura tal y como dejó escrito en sus Reflexiones sobre la Arquitectura ${ }^{13}$. Su influencia se dejó sentir también en el funcionamiento de la Escuela de las Tres Nobles Artes de Cádiz, donde su dictamen favorable hizo que pasaran la censura y se aprobaran en la Academia en 1794 las Ordenanzas de la Institución ${ }^{14}$.

El arquitecto que sirve de puente entre la Arquitectura Barroca y la Neoclásica en Cádiz es Torcuato Cayón de la Vega (1725-1783) ${ }^{15}$ Académico de Mérito por la Arquitectura en la Real Academia de Bellas Artes de San Fernando el 19 de junio de $1763^{16}$. Su figura guarda similitud con la de Ventura Rodríguez, su yerno, porque en sus obras se trasluce la formación y el seguimiento de los modelos del Barroco romano que ambos habían conocido a través de las estampas. Cayón como discípulo de Vicente Acero y de su tío Gaspar Cayón trabajó en las obras más importantes del Cádiz de esos años: maestro mayor de la catedral en 1757, arquitecto mayor de Cádiz en 1767, e iniciador de las iglesias de San José, San Pablo o la Santa Cueva, así como la iglesia de San Juan Bautista de Chiclana, arquitecturas todas planteadas en un Barroco clasicista de gran sobriedad que como en el caso de Ventura Rodríguez, se han querido interpretar como el inicio del Neoclasicismo en Cádiz ${ }^{17}$.

Pedro Ángel de Albisu (1753-1817), guipuzcoano de Zumárraga fur responsable de la introducción del Neoclasicismo en Cádiz. Continuó la obra de Cayón primero en el Arsenal de la Carraca en 1779 y más tarde como Arquitecto Mayor de Cádiz desde el 16 de octubre de 1779. Albisu encarna el prototipo de arquitecto de sólida formación adaptado a los nuevos tiempos. En la Academia de San Fernando estudió Geometría y Arquitectura que completó con Dibujo y Perspectiva. En los Reales Estudios de San Isidro amplió su formación en

13 "Tiene la arquitectura de común con otras Artes la observación de la unidad, de la verdad, o verosimilitud, de la costumbre, del tematismo, o estación, y de la naturaleza; que todas se encierran en lo que es ordenación, decoro y economía". MOLINA Y ZALDÍVAR, Gaspar. Reflexiones sobre la arquitectura, ornato y música del templo, contra los procedimientos sin consulta de la Escritura Sagrada, de la disciplina rigurosa $\gamma$ de la crítica facultativa. Madrid, D. Joachin de Ibarra, 1785. p. 205.

14 https://realacademiabellasartessanfernando.com/es/archivo-biblioteca. Actas de la Junta Particular de 30 de noviembre de 1794.

15 FALCÓN MÁRQUEZ, Teodoro. Torcuato Benjumeda y la Arquitectura Neoclásica en Cádiz. Cádiz: Excmo. Ayuntamiento de Cádiz, 1974. p. 45. El autor analiza el significado de la obra de Cayón como maestro de Torcuato Benjumeda y Miguel de Olivares que representarán el paso al Neoclasicismo.

16 https://realacademiabellasartessanfernando.com/es/archivo-biblioteca. Relación general de académicos (17522019). Consultado 30-11/2020.

17 CHUECA GOITIA, Fernando. Ventura Rodríguez y la escuela barroca romana. VV.AA. El arquitecto D. Ventura Rodríguez (1717-1785). Madrid, Excmo. Ayuntamiento de Madrid, 1983. p.11y ss. El autor sostiene que Rodríguez como discípulo de Juvara, perteneció a la escuela barroca romana y copió sus diseños aún en aquellas obras que parecían más personales como la iglesia de San Marcos de Madrid (1749-1753). 
Matemáticas y Geografía. Obtuvo el grado de Académico Supernumerario en 1780 y viajó a la Isla del León para realizar estudios de arquitectura naval y trabajar en el Arsenal de La Carraca $^{18}$.

Desde muy temprano y apoyado por los méritos y certificaciones del secretario de la Academia, Antonio Ponz, Albisu bien a las órdenes de la Corona o continuando la labor de Torcuato Cayón trabajó en la obra del Ayuntamiento de San Fernando, en las Casas Consistoriales de Cádiz o en la Colegiata de Jerez de la Frontera. Su huella es notable porque hasta su fecha de jubilación en 1816 fue Director de Arquitectura en la Academia de Nobles Artes de Cádiz donde contribuyó a la formación de una generación de arquitectos gaditanos ${ }^{19}$.

Discípulos directos de Torcuato Cayón son Miguel de Olivares y Guerrero y Torcuato José Benjumeda y Laguada quienes fueron instruidos en la arquitectura como alumnos de la escuela que tenía en su propia casa y por su colaboración en las obras del maestro.

Miguel de Olivares y Guerrero (1748 -1813) fue siempre un arquitecto académico, que aunque trabajara fuera de Madrid, siempre mostró su dependencia y respeto hacia los criterios y orientaciones de la Academia de San Fernando de la que fue alumno en 1766 con 16 años como acreditan los Registros de Matrícula ${ }^{20}$. Trabajó con Torcuato Cayón como aparejador desde 1772 en la Colegiata de Jerez y a la muerte de éste en 1783 se incorporó como arquitecto a la obra de la Catedral de Cádiz. Las disposiciones dictadas en 1777 le obligaron a presentarse a las pruebas para acceder a académico de mérito para poder asumir la dirección de obras. Olivares fue nombrado académico de mérito por la arquitectura el 2 de abril de 1787 tras haber superado las pruebas para arquitecto y acreditar su participación en obras bajo la dirección de un arquitecto aprobado por la Academia como era el caso de Cayón. Presentó un proyecto de "Panteón para un Señor Grande y su familia" que firma y rubrica y especifica que "fue delineado el 28 de enero de $1787^{\prime 21}$. Los tres dibujos remiten al Panteón de Agripa en Roma un modelo de referencia, en el que Olivares dispuso un acceso a través de un pórtico tetrástilo de orden

18 GARMENDIA ARRUEBARRENA, José. Pedro Ángel de Albisu, un arquitecto desconocido. Boletín de la Real Sociedad Bascongada de Amigos del País. Tomo 36, 1980 p. 406-409.

19 FALCÓN MÁRQUEZ, Teodoro, op. cit., P. 50.

20 PARDO CANALÍS, Enrique. Los Registros de Matrícula de la Academia de San Fernando de 1752-1815. Madrid, C.S.I.C., 1967 p.81. http://www.cervantesvirtual.com/portales/bellas_artes_san_fernando/obra-visor/real-academia-debellas-artes-de-san-fernando-secretaria-libros-de-matriculas-de-la-escuela-especial-de-arquitectura-1752-1815/ $\mathrm{html} /$. Manuscrito digitalizado 3/300, Fol.107v-108r.

21 ARBAIZA, Silvia, HERAS, Carmen. Arquitectura funeraria y conmemorativa. Exposición abril-mayo Academia. Boletín de la Academia de Bellas Artes de San Fernando. Número 77, 1993. p. 448. Las comisarias reproducen los dibujos presentados por Olivares registrados en el Archivo y Museo de la Academia con los números A-4833 y A-4834. 
dórico, muros lisos con pilastras pareadas y una esbelta cúpula sobre tambor coronada por un obelisco. El modelo de templo de planta central fue retomado por el arquitecto con sobriedad neoclásica en la ermita de San Pedro de Ubrique de 1801. Investigaciones recientes han querido ver la huella de Olivares en la ermita de San Juan de Letrán del mismo Ubrique, cuna del arquitecto, que a falta de cúpula repite el modelo de fachada con pilastras lisas y pareadas.

El control de la Academia no abandonó a Miguel de Olivares pues poco después de su nombramiento como Académico de Mérito disensiones con su colega José Prat sobre la manera de levantar adecuadamente las pechinas de la cúpula de la catedral de Cádiz, dieron lugar a que se comisionara al teniente director de arquitectura de la Real Academia de San Fernando, Manuel Machuca Vargas (1750-1799), para que informase sobre la marcha de las obras en la catedral una vez fallecido Torcuato Cayón. Machuca envió a Madrid los planos del estado de la catedral y fue designado su arquitecto director en 1790 mientras que Olivares fue nombrado arquitecto constructor ${ }^{22}$.

Torcuato José Benjumeda y Laguada (1757-1836) encarna la evolución desde el barroco clasicista de Torcuato Cayón, su tío y maestro, al romanticismo decimonónico. Como bien documenta Teodoro Falcón, las primeras obras de Torcuato Benjumeda son continuación de las ya planeadas por Cayón fallecido en $1783^{23}$. Las iglesias de San Juan Bautista de Chiclana, San José de Puerto Real, el Oratorio de la Santa Cueva o la iglesia de San José de Cádiz son la muestra del seguidismo y el recuerdo de los modelos del Barroco romano que Benjumeda supo aligerar al dotar a sus fachadas de una mayor planitud con pilastras adosadas, claramente un avance a los modelos codificado por Ventura Rodríguez. En la iglesia de San José extramuros de Puerta de Tierra, Benjumeda siguió los diseños de Torcuato Cayón y recurrió para los campanarios laterales a la arquitectura de Serlio que Francesco Borromini (1599-1667) había empleado en Sant' Agnese en Agone de Roma (h.1653). La parroquia de San José ha sido muy transformada en el siglo XX y en la actualidad presenta un moderno bicromatismo y la ausencia del grupo escultórico que coronaba el frontón triangular, un escudo sostenido por dos ángeles obra del académico Cosme velázquez, un motivo que repite en otras obras ${ }^{24}$.

22 GARCÍA MELERO. 1991 op. cit. p. 301. El autor describe todo el proceso de designación aunque las obras de la catedral se interrumpieron pocos años después cuando aún no se habían terminado ni la sacristía ni el trascoro.

23 FALCÓN MÁRQUEZ. Torcuato... op. cit. p. 58.

24 VASSALLO PARODI, Juan Luis. La iglesia parroquial de Cádiz. Academia. Boletín de la Real Academia de Bellas Artes de San Fernando. $\mathrm{N}^{\circ}$ 40, 1975. p.101. El escultor Vassallo denunció en la sesión académica del día 21 de octubre de 1974 los daños causados en San José donde el grupo escultórico había sido despedazado por los bomberos de Cádiz, siguiendo órdenes del Ayuntamiento, por amenazar ruina. 


\section{Figura 1}

\section{Iglesia de San José de Cádiz. Hauser y Menet, Madrid}

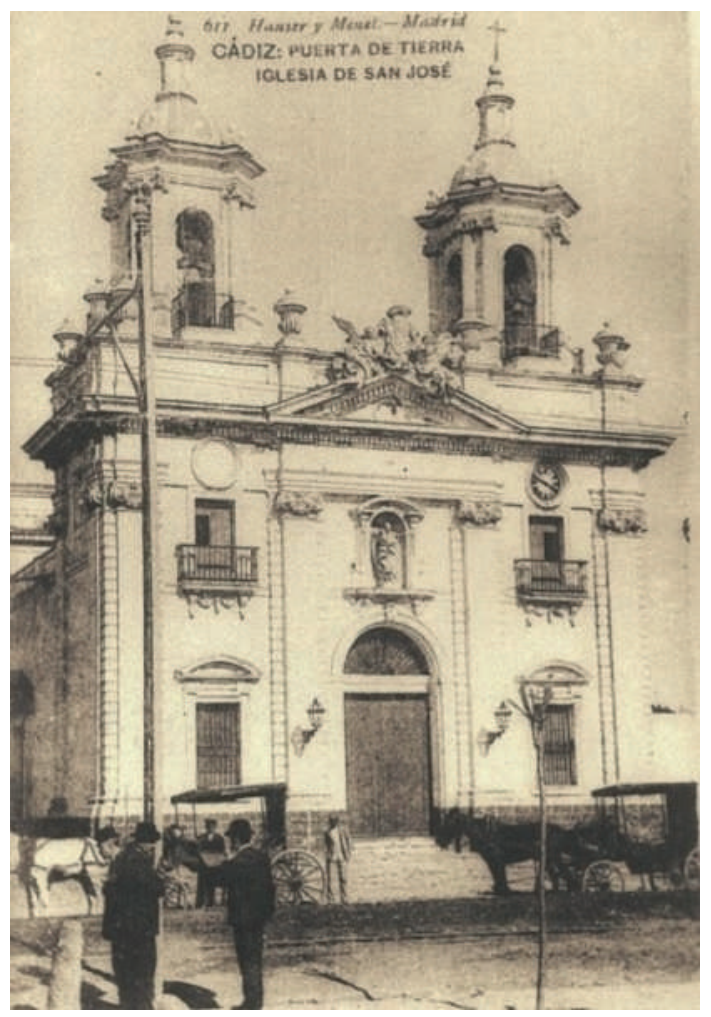

Desde 1789 Benjumeda fue Teniente de Arquitectura de la Academia de Nobles Artes de Cádiz donde llegará a Director de Arquitectura tras la jubilación de Albisu en 1816. Por ausencia de esta último se incorporó a las tareas de Maestro Mayor de Cádiz lo que desató la indignación de Miguel de Olivares quien denunció que no poseía la titulación de Académico de Mérito por la Arquitectura como era preceptivo para ocupar tal puesto y en su escrito al Ayuntamiento exponía "que como arquitecto establecido en esta ciudad, no puede mirar con indiferencia el deshonor que se le infiere con la elección para Maestro mayor de obras de un sujeto que carece de igual graduación a la suya..." ${ }^{25}$. Los reparos de Olivares no hicieron variar la postura de la Institución pero si espoleó a Benjumeda a regularizar su situación ante la Real Academia de Bellas Artes de San Fernando solicitando en 1793 ser reconocido como Académico de Mérito.

El examen fue un episodio excepcional en el funcionamiento de la Academia porque Benjumeda solicitó no desplazarse a Madrid para realizar el preceptivo examen, alegando la 
necesidad de atender las obras que tenía fuera y dentro de Cádiz ${ }^{26}$. Previo informe del gobernador de Cádiz, Sr. Marqués de Fonsdevilla, del marqués de Ureña y del teniente director Manuel Machuca entonces en Cádiz trabajando en la Catedral, se le concedió esa posibilidad y se le encargó como prueba de pensado "Casa para Consulado Magnífico en Puerto de Mar" con todas sus oficinas correspondientes, informe facultativo y cálculo de la obra que el candidato debería realizar en Cádiz. En la junta ordinaria de 5 de enero de 1794 el secretario de la Academia, Isidoro Bosarte, informó de que el candidato había pasado las pruebas para la graduación de Académico de Mérito en casa del gobernador Sr. Marqués de Fonsdevilla en los términos que la Academia había establecido y atendido el correspondiente examen oral ante el Marqués de Ureña comisionado para este fin. El candidato, en presencia de varios caballeros, respondió satisfactoriamente a las preguntas de Estereotomía, armaduras y uso de las planchetas ${ }^{27}$. El voto favorable de 24 de los 25 vocales designados para la prueba declaró a Torcuato José Benjumeda Laguada, nacido en el Puerto de Santa María, Académico de Mérito por la arquitectura el 1 de abril de $1794^{28}$.

El aspecto más relevante de esta prueba de pensado fueron los dibujos para la Aduana, una espectacular estructura arquitrabada con la fachada recorrida por columnas gigantes que cobijan los dos pisos y que se remata con una balaustrada. El cuerpo central avanzado se cierra con una cúpula con óculo e interior decorado con casetones. Los cuerpos laterales se cubren con cupulillas coronadas por pirámides ${ }^{29}$. Todo el conjunto guarda relación con la denominada arquitectura de las sombras como la del hoy Museo del Prado de Juan de Villanueva ${ }^{30}$.

En 1793 el tema de pensado para los premios de primera clase había sido "En un puerto de mar idear una Aduana con todas las oficinas que le correspondan, unida a esta una Casa de Contratación con el Tribunal competente, proyectando este edificio con su plaza

26 https://realacademiabellasartessanfernando.com/es/archivo-biblioteca. Acta de la Junta ordinaria de 7 de abril de 1793 , fol. $234 \mathrm{r}-234 \mathrm{v}$.

27 https://realacademiabellasartessanfernando.com/es/archivo-biblioteca. Acta de la Junta ordinaria de 5 de enero de 1794 , fol. 234r-234v.

28 https:/www.realacademiabellasartessanfernando.com/es/archivo-biblioteca/archivo/relacion-general-deacademicos.

29 GARCÍA MELERO...op.cit.p. 317y ss. El autor detalla el proyecto para el examen y la memoria presentada por Benjumeda así como los dibujos que aparecen firmados el 19 de Noviembre de 1793. Los dibujos pertenecen al Museo de la Academia de San Fernando y fueron reproducidos para el trabajo. La situación especial por la que atravesamos nos ha impedido conseguido reproducciones ya que no están digitalizadas, ni acceder al número de inventario de los dibujos.

30 CHUECA GOITIA, Francisco. Juan de Villanueva: su significado en la historia de la Arquitectura Española. VV.AA.: Juan de Villanueva arquitecto 1739-1811. Madrid, Ed. Ayuntamiento de Madrid, 1982. p. 41. Chueca denominó así a esas arquitecturas cuyos diferentes cuerpos arrojan sombras profundas como había hecho Villanueva y antes E.L. Boullée. 
principal, y de ella la correspondiente baxada para el embarco y desembarco de los navíos" un tema muy similar al encargado a Benjumeda ${ }^{31}$. El premio de primera clase fue para el arquitecto Joseph Joaquin de Troconiz, dibujos que no conocemos pero que podemos relacionar con un dibujo de autor anónimo "Alzado de la fachada principal de una aduana fortificada en un embarcadero" que nos trae a la memoria la Cárcel Real de Cádiz con su estructura arquitrabada y su pórtico tetrástilo avanzado que Torcuato Benjumeda inició en $1794^{32}$.

Figura 2

Anónimo Español: Alzado de la fachada principal de una aduana fortificada en un embarcadero. Academia San Fernando, Museo, Inv. A-1148

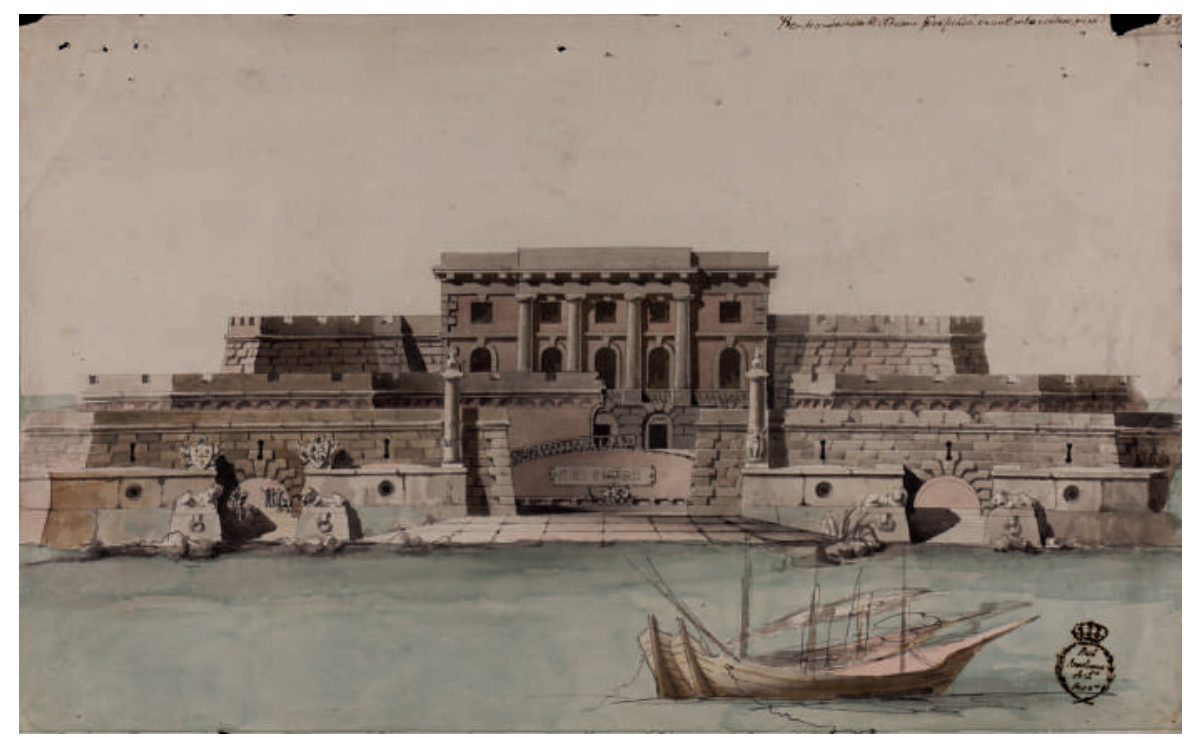

La Cárcel Real que podría entenderse como el manifiesto de la nueva arquitectura se levantó en el Campo del Sur como edificio exento para evitar problemas en su funcionamiento ${ }^{33}$. La rotundidad de su arquitectura se manifiesta con un cuerpo central avanzado con triple acceso, arcos entre dinteles y disco central, ordenamiento que también se repite

31 VV.AA. Hacia una nueva idea de Arquitectura. Premios generales de arquitectura de la Real Academia de bellas Artes de San Fernando (1753-1831). Madrid: Real Academia de Bellas Artes de San Fernando y Comunidad de Madrid, 1992. p.135.

32 ARABASF: Dibujos de Arquitectura. “Anónimo español. Alzado de la fachada principal de una aduana fortificada en un embarcadero". Siglo XVIII. No Inventario A-1149.

33 VILLANUEVA, Luis de. Don Torcuato José de Benjumeda. (1765-1836). Revista Nacional de Arquitectura. № $100,1946$. p. 49. El autor expone que la disposición de la fachada con un gran pórtico flanqueado por dos cuerpos apilastrados se retomará en el edificio del Ayuntamiento gaditano. 
en los muros laterales, un motivo que Benjumeda tomó de Sebastian Serlio ${ }^{34}$ y empleó en otras obras al igual que el remate escultórico sobre la cartela del cuerpo central, en este caso dos leones rampantes que sostienen el escudo real ${ }^{35}$.

Figura 3

\section{Cádiz, Cárcel Real}

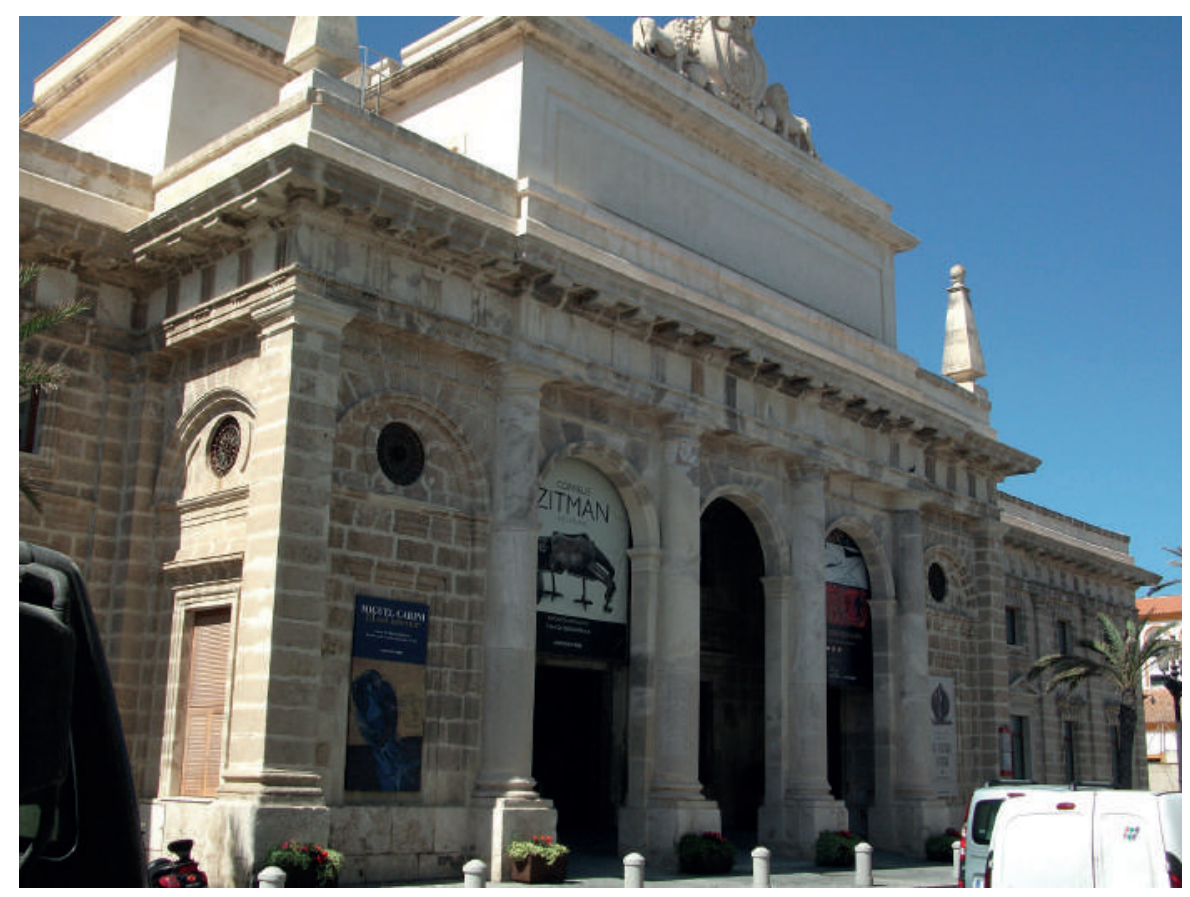

Foto de la autora, 2014

Uno de los primeros expedientes a los que tuvo que enfrentarse Benjumeda fue el envío a censura de la Comisión de Arquitectura por los comisionados del Ayuntamiento de Cádiz de los planos para la construcción de un cementerio extramuros de la ciudad que debía ajustarse a la Real Cédula de 3 de abril de 1787 que prohibía expresamente enterrar en las iglesias y ordenaba la construcción de cementerios fuera de la ciudad. Para la ocasión Benjumeda delineó unos planos verdaderamente grandiosos que como recogen las Actas de 4 de febrero de 1802 la Comisión de Arquitectura consideró que eran susceptibles de mayor sencillez, suprimiéndose las fajas e impostas, archivoltas y demás ornamen-

34 SERLIO, Sebastian. 1552.Libro quarto de architectura en el que se trata las cinco maneras de como se puede adornar los hedificios que son Thoscano, Ionico y Corinthio y Compuesto, con los exemplos de las antigüedades, las quales de la mayor parte se conforman con la doctrina de Vitruvio. Traducido por Francisco de Villalpando, Toledo. Planchas XLVI y XLVII.

35 No nos consta que el proyecto pasase por la Comisión de Arquitectura de la Academia, Teodoro Falcón (1974, p.72) dice que fue aprobado por el Consejo de Castilla en 1792 antes del nombramiento de Benjumeda como académico de mérito. 
tos tanto en el interior como en el exterior del cementerio. También se advirtió falta de solidez en algunas partes del edificio, principalmente en la capilla y los pórticos que la circundaban. Era parecer de la Comisión que dicha capilla debía hacerse más capaz y dar a todo el edificio un carácter más análogo a su destino lo que contribuiría a su mejor dispendio. Este fue el dictamen de la Junta que la comisión recomendaba comunicar confidencialmente a Benjumeda para que las pusiera en ejecución en los nuevos diseños, cuyos borradores se enviarían a censura antes de ponerlos en limpio. La Comisión también recomendaba que se comunicara al arquitecto que el proyecto no era malo aunque era susceptible de mayor perfección y economía y que por ello se le hacían particularmente las advertencias según firma Silvestre Pérez, entonces secretario de la Comisión de Arquitectura nombrado mediante una Real orden de 10 de marzo de $1799^{36}$. Parece que el proyecto con las oportunas correcciones fue aprobado en 1803 aunque nunca se llevó a cabo. En 1816 se edificó un camposanto con cinco patios y una capilla sencilla de pequeñas dimensiones ${ }^{37}$.

Figura 4

Parroquia de San Juan Bautista de Chiclana

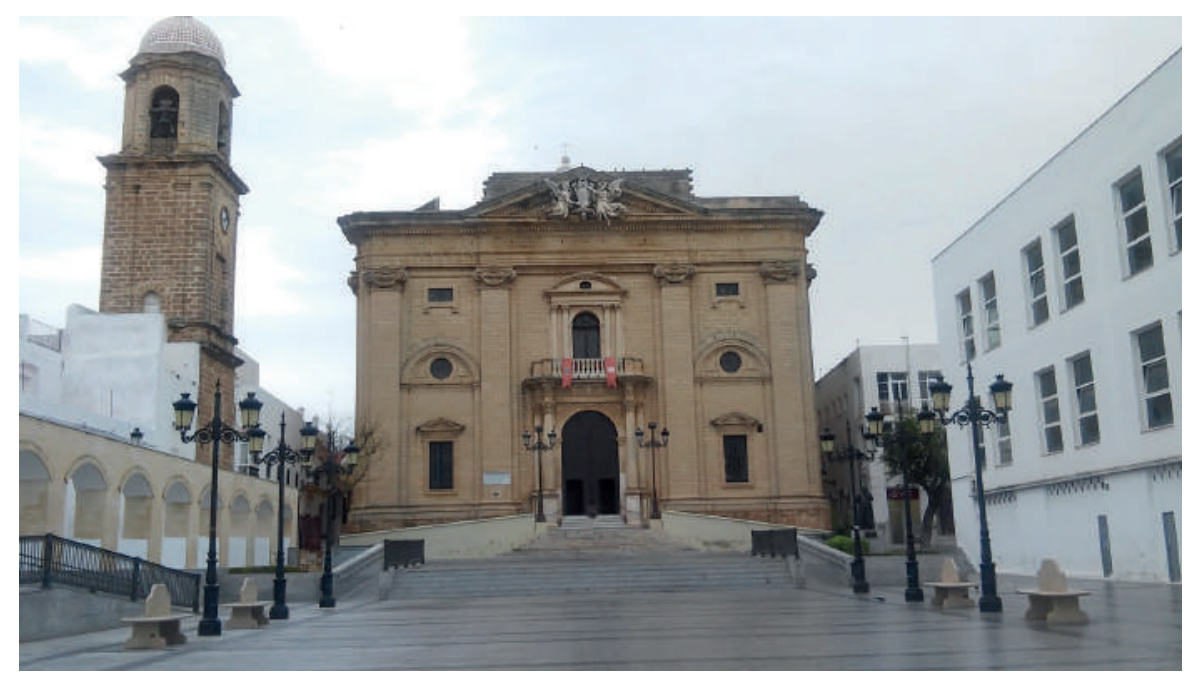

Foto de la autora, 2014

\begin{abstract}
36 http://www.cervantesvirtual.com/obra-visor/real-academia-de-bellas-artes-de-san-fernando-comision-dearquitectura-libros-de-actas-1786-1959-17/html/1bd10c92-abdb-11e1-b1fb-00163ebf5e63_2.html Acta de 4 de febrero de 1802 , fol. 337r.

37 FALCÓN MÁRQUEZ, Teodoro. Torcuato...op.cit. p. 76-77. La lámina XXVII del referido texto muestra el diseño del plano General del cementerio General de Cádiz de agosto de 1819; la lámina XXVIII muestra los planos de la capilla para cementerio de 1802 que se conservan en el Archivo Histórico de Cádiz. Ninguno de tales diseños se llevaron a la práctica inaugurando después de la Guerra de la Independencia un camposanto mucho más sencillo y funcional.
\end{abstract}


Una de las obras más interesantes que Torcuato Benjumeda heredó de su tío y padrino, Torcuato Cayón, fue la iglesia parroquial de San Juan Bautista de Chiclana iniciada en 1776 y cuya obra a la muerte de Cayón en 1783 estaba apenas avanzada. Muchas son las concomitancias con otra obra de Cayón y Benjumeda como es San José de Cádiz en donde se había empleado el mismo tipo de pilastra adosada de orden jónico con guirnaldas entre las volutas. Para Chiclana se delineó una planta salón de tres naves y testero plano con pilares cruciformes.

La fachada que parece se levantó entre 1791 y 1797 aprovecha la perspectiva del emplazamiento para elevar su espectacular estructura arquitrabada recorrida por pilastras lisas coronada por cornisa corrida y rematada por frontón central adornado por el grupo escultórico de dos ángeles que sostienen el blasón de Fernando VII, obra de Cosme Velázquez ${ }^{38}$. El progreso de la obra debió de ser lento por la falta de fondos que algunos benefactores trataron de remediar sin que al comienzo de la Guerra de la Independencia el templo tuviera una cubierta acorde. El profesor Falcón menciona la existencia de cuatro planos fechados en 1816 con diseños para la capilla mayor y las laterales del mismo Benjumeda si bien menciona otros diseños en colección particular fechados en $1806^{39}$. Según los datos proporcionados por las Actas de la Comisión de Arquitectura de la Academia del 30 de enero de 1806 el Secretario de la misma, Silvestre Pérez, dice haber presentado tres diseños suyos delineados para la conclusión de la iglesia parroquial de la villa de Chiclana de la Frontera que corregían y simplificaban los de Antonio Jiménez que anteriormente había visto y desaprobado la Comisión que sin embargo sí aceptó los suyos ${ }^{40}$. El que Silvestre Pérez presentara unos diseños alternativos sólo podía deberse a que los recibidos no reunían las características de majestuosidad, sencillez y enlace con la tradición que la Comisión de la Academia solicitaba. La Junta ordinaria de 2 de febrero de 1806 aprobó los diseños una vez pasada la censura de la Comisión de Arquitectura. La resolución de este expediente plantea

38 Cosme Velázquez Merino (1755-1837) había colaborado con Benjumeda en la iglesia de San José también lo haría en la Santa Cueva con un tabernáculo de ricos mármoles que seguía los modelos de Bernini. Fue director de Escultura en la Escuela de Bellas Artes de Cádiz. FERREIRA FERNÁNDEZ, Myriam. Nuevas aportaciones sobre el escultor Cosme Velázquez (1755-1837). Trocadero. № 27, 2015. p. 131 y ss.

39 FALCÓN MÁRQUEZ, Teodoro. La iglesia de San Juan Bautista de Chiclana. II centenario (1814-2014). Trocadero: Revista de Historia moderna y contemporánea. $\mathrm{N}^{\circ} 26,2014$. p. 7. El autor esboza un estudio detallado del templo desde sus orígenes hasta mediados del siglo XIX cuando fue completada la obra.

40 ARABASF: Comisión de arquitectura. Libro de Actas, junta de 30 de enero de 1806. Leg. 140/3. Digitalizado en http:// www.cervantesvirtual.com/obra-visor/real-academia-de-bellas-artes-de-san-fernando-comision-de-arquitecturalibros-de-actas-1786-1959-17/html/1bd10c92-abdb-11e1-b1fb-00163ebf5e63_2.html Acta 30 de enero de 1806 fol.1v-2r. Junta ordinaria de 5 de febrero de 1806 fol. 221 donde se da trámite a las decisiones de la Comisión de Arquitectura presentadas por Silvestre Pérez. 
sin embargo una incógnita, ¿de acuerdo a qué planos se concluyó la iglesia?. Pensamos que el diseño de la planta de la parroquial de Chiclana fue el que tuvimos ocasión de ver expuesto en el Museo de Chiclana en 2014 con la firma de Silvestre Pérez como muestra de haber superado la censura de la Academia una vez rectificados los diseños presentados. Es sin embargo extraño que en ningún momento las Actas de la Comisión mencionen a Torcuato Benjumeda.

En la Junta de la Comisión de Arquitectura de 1804 el supernumerario Pedro Ángel Albisu presentó a censura los diseños para la reparación del muelle de Puerto Real con su presupuesto que fueron rechazados en la Junta del 30 de diciembre de 1805 por considerar que los costes no eran reales ya que se necesitaría dar mayor solidez a las obras además de suprimirse el ornato innecesario de la casilla. Se solicita que arquitectos facultados en Cádiz presenten nuevos diseños para censura. Una nueva Junta de 24 de abril de 1806 acepta los planos arreglados por el arquitecto académico Torcuato Benjumeda y aprueba las obras proyectadas a falta del cálculo del coste necesario para darle la solidez requerida lo que impidió que se realizara ${ }^{41}$. Los planos alzados y perfiles en punto mayor de los muelles, cortina y plantíos de la Villa de Puerto Real firmados por Torcuato Benjumeda en 1808 se conservan en colección particular ${ }^{42}$.

El control de la Academia fue una realidad en toda obra pública de importancia y las Casas Consistoriales de Cádiz no fueron una excepción. El acta de la Junta de la Comisión de Arquitectura de 5 de noviembre de 1806 recoge que el académico arquitecto D. Torcuato Josef de Benjumeda había remitido a censura cinco diseños en borrador ejecutados para la reedificación de la casa capitular de la ciudad de Cádiz que hacía tiempo estaba apuntalada "a fin de que hallándose la junta conforme o advirtiendo correcciones que tuviera por conveniente, quede enmendada al tiempo de ponerlos a limpio". Una vez examinados, la Comisión los aprobó. La Junta del 29 de octubre de 1807 da cuenta de que los cinco diseños presentados a censura "confidencialmente" por Benjumeda que manifestaban las reformas que se intentaban hacer en las casas consistoriales de Cádiz parecieron acertados y por consiguiente aprobados ${ }^{43}$. Los diseños de Benjumeda reproducen casi

41 http://www.cervantesvirtual.com/obra-visor/real-academia-de-bellas-artes-de-san-fernando-comisionde-arquitectura-libros-de-actas-1786-1959-21/html/337d6a3e-abdb-11e1-b1fb-00163ebf5e63_19.html. 1805 ， fol. 407r-408v. 1806, fol. 4v-5r.

42 FALCÓN MÁRQUEZ, Teodoro. Torcuato...op.cit: p. 13. El autor los documenta en la colección Solís de Cádiz.

43 http://www.cervantesvirtual.com/obra-visor/real-academia-de-bellas-artes-de-san-fernando-comision-dearquitectura-libros-de-actas-1786-1959-21/html/337d6a3e-abdb-11e1-b1fb-00163ebf5e63_19.html. Año 1806, fol. 12v. Año 1807, fol. 28v. 
exactamente la imagen de la fachada actual excepto los ornamentos decorativos de gusto ecléctico que se añadieron con posterioridad ${ }^{44}$. La espectacular fachada se convirtió en el foco central de la plaza de San Juan de Dios que desde 1792 Benjumeda regularizó hasta la Puerta del Mar. Algunos han querido ver en esta obra emprendida ya en 1816, con basamento almohadillado con arquerías y cuerpo central a modo de galería con columnas de orden gigante rematado por frontón y coronado por una balaustrada, un atisbo de palladianismo a la inglesa que se justificaría con cierto simplismo por las relaciones comerciales de Cádiz con Inglaterra ${ }^{45}$.

El celo de la Comisión de Arquitectura de la Academia en su cometido de velar por la buena arquitectura se aprecia en la presentación a censura en 1807, de forma confidencial, los diseños del académico arquitecto D. Bartolomé Ojea (u Ojeda) Matamoros (1741-1817) para erigir el altar mayor y tabernáculo exento de mármol estatuario de Italia en la iglesia prioral de El Puerto de Santa María. La Junta acordó no aprobar los diseños por carecer de buenas proporciones, de gusto y de elegancia y recomendó que cuando se presentase de nuevo a censura, una vez arreglados fueran acompañados de la planta y alzado del presbiterio donde se había de colocar para ver si todo guardaba la magnitud y buena proporción que correspondía $^{46}$. En el acta de la junta del 3 de septiembre se comunica que el maestro arquitecto D. Miguel de Inclán Valdés (1774-1853) había presentado dos diseños alternativos para el tabernáculo haciendo la observación de que el arquitrabe interior de la cúpula no estuviera interrumpido por las franjas verticales sino que fuera continuo tanto por dentro como por fuera ${ }^{47}$. Los cuatro diseños definitivos de Inclán fueron aprobados en una nueva junta de 29 de octubre ${ }^{48}$. El asunto del tabernáculo de El Puerto de Santa María causó un enorme revuelo por el rechazo y enmiendas a los diseños primeros de Ojea Matamoros, Académico de Mérito desde 1788 y un profesional de prestigió. La obra se demoró en el tiempo y fue Torcuato Benjumeda, maestro mayor de Cádiz, una vez fallecido Ojeda, quien

\footnotetext{
44 FALCÓN MÁRQUEZ, Teodoro. Torcuato...op.cit. p. 68.

45 VILLANUEVA. 1946, P. 50.
}

46 ARABASF: Actas de la Comisión de Arquitectura, Libro 1806-1823), Leg. 3/140, fol.22. Acta de 3 de junio de 1807. http:// www.cervantesvirtual.com/obra-visor/real-academia-de-bellas-artes-de-san-fernando-comision-de-arquitecturalibros-de-actas-1786-1959-22/html/398063fo-abdb-11e1-b1fb-00163ebf5e63_12.html. Fol. 22r.

47 Juan Miguel de Inclán Valdés era maestro arquitecto en 1807. Fue nombrado académico de mérito el 6 de mayo de 1814 y ascendido a teniente director de arquitectura el 14 de diciembre de 1822. El 11 de junio de 1827 era ya Vicesecretario de la Academia. https://www.realacademiabellasartessanfernando.com/es/archivo-biblioteca/ archivo/relacion-general-de-academicos.

48 ARABASF: Actas de la Comisión de Arquitectura, Libro 1806-1823), Leg. 3/140, Acta de 3 de septiembre de 1807, fol.25r. Acta de 29 de octubre de 1807, fol. 28v. 
asumió la obra que para varios autores debe entender como la imposición desde la Academia de San Fernando de los gustos neoclásicos en los templos ${ }^{49}$.

\section{Figura 5}

\section{El Puerto de Santa María. Tabernáculo iglesia Mayor Prioral}

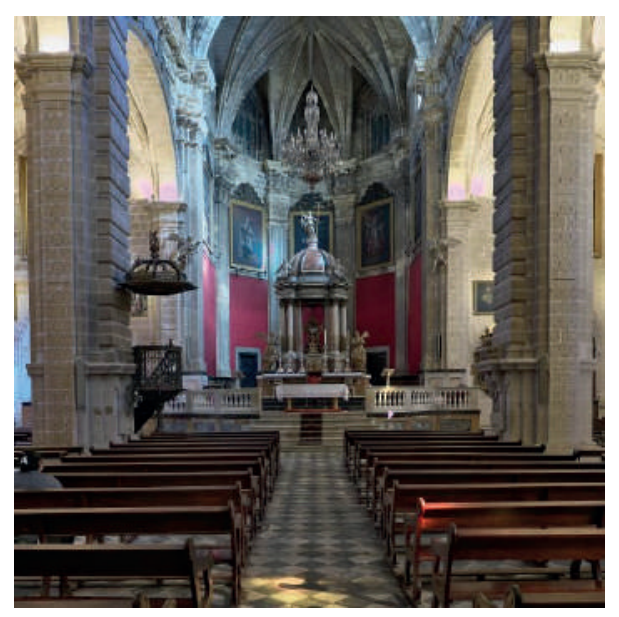

Una vez terminada la Guerra de la Independencia la Academia y su Comisión de Arquitectura intentó seguir manteniendo el control sobre la arquitectura y principalmente sobre la formación de los arquitectos y maestros de obra. Una Real Cédula de 2 de octubre de 1814 recordó las disposiciones dictadas por Carlos III y Carlos IV y ratificó la abolición de los privilegios de algunos pueblos de otorgar títulos de arquitectos y maestros de obras y la provisión del 5 de enero de 1801, declarando nulos los títulos expedidos por prelados, cabildos, ayuntamientos o gremios. En un memorial redactado por el director de arquitectura Julián de Barcenilla y dirigido al secretario de la Academia, Martín Fernández de Navarrete (1765-1844) el 30 de agosto de 1816 se manifiesta que a pesar de las disposiciones vigentes apenas se había conseguido que las autoridades, cuerpos y prelados se prestasen ni aun advertirlos a preservar los planos de las obras presentados y censurados por la Academia. La situación debía ser habitual porque Torcuato José de Benjumeda, arquitecto académico de Cádiz denunció hacia 1819 que en la ciudad y pueblos de la provincia se practicaba "la arquitectura con desorden por profesores intrusos en inobservancia de las Reales Órdenes". También denunciaba que se tratase de concluir la obra de la Catedral

49 RECIO MIR, Álvaro. La transformación neoclásica de la prioral de El Puerto de Santa María (Cádiz): tabernáculo, presbiterio y coro. Laboratorio de Arte, $\mathrm{n}^{\circ}$ 19, 2006. p. 303-327. También sobre el tabernáculo ALONSO DE LOS RIOS FERNÁNDEZ, Lorenzo. Barroco e Ilustración. El retablo en Cádiz durante las últimas décadas del siglo XVIII. Actas III congreso internacional del Barroco Americano: territorio, Arte espacio y Sociedad. Sevilla, 2001. p. 557 y ss. 
nueva de Cádiz sin contar con ningún arquitecto aprobado ${ }^{50}$. Como director de la Academia gaditana, Benjumeda participó en el debate planteado en esos años que tuvo eco en la Comisión de Arquitectura donde se denunció el error del Ayuntamiento de Cádiz por nombrar alarifes sin tener potestad para hacerlo ${ }^{51}$. Las quejas de Benjumeda aumentaron cuando reclamó ante la Real Academia de Bellas Artes de Cádiz sentirse postergado como director de arquitectura frente a los emolumentos que recibían los directores de pintura o escultura ${ }^{52}$.

Desde 1820 Benjumeda, a pesar de los problemas en su cargo que derivaron en problemas de salud ${ }^{53}$, centró su actividad en avanzar las obras que la guerra había interrumpido pero sobre todo en emprender proyectos urbanos destinados al embellecimiento de la ciudad con la construcción de equipamientos públicos propios de una ciudad burguesa volcada en el comercio. Proyectó plazas en espacios liberados que desde 1834 las medidas desamortizadoras incrementaron, diseñó un mercado de abastos, procuró la ampliación de los paseos y lugares públicos, proyectos todos que asumirá su sucesor como maestro mayor, Juan Daura ${ }^{54}$.

La figura de Juan Daura (1786-1844) sirve de enlace entre el neoclasicismo institucional y académico y el eclecticismo isabelino que ya representarán arquitectos como Juan de la Vega (1806-1883). Su carrera en Cádiz se inicia en fecha tardía, 1831, cuando se presenta en la ciudad para solicitar la plaza de segundo Arquitecto Mayor. Había recibido formación en arquitectura y matemáticas en la Academia de Tarragona y en la de Barcelona para incorporarse como delineante hidráulico en las Obras del Puerto de Tarragona hasta el inicio de la Guerra de Independencia que le recibe como militar en una compañía de zapadores. Héroe en la contienda por lo que recibió numerosas condecoraciones, sin abandonar la carrera militar marchó a Madrid para continuar sus estudios de arquitec-

\section{ARABASF: Leg. 25-2/2.}

51 http://www.cervantesvirtual.com/obra-visor/real-academia-de-bellas-artes-de-san-fernando-comision-dearquitectura-libros-de-actas-1786-1959-21/html/337d6a3e-abdb-11e1-b1fb-00163ebf5e63_19.html. Acta de 23 de febrero de 1820. Folio 187r.

52 PÉREZ MULET, Fernando. De Arquitectura, Pintura y Ornamentación". ANTIGÚEDAD, María Dolores., CIRICI, Juan Ramón (Coord. Y Ed): Arquitectura y ciudad en España de 1845 a 1898. Ed Universidad de Cádiz e UNED, 2000. P.15. El autor recoge las Actas de la Junta de la Real Academia de Nobles Artes de Cádiz de 1 de noviembre de 1826 en la que el arquitecto reclamó la misma consideración para los profesionales de la arquitectura que para los pintores.

53 FALCÓN MÁRQUEZ, Teodoro. Torcuato...op.cit p. 56. El autor comenta el expediente y suspensión de empleo y sueldo por el derrumbe de la plaza de toros en 1820. Con posterioridad estos sinsabores le llevaron a una depresión nerviosa.

54 CIRICI NARVÁEZ, Juan Ramón. Arquitectura isabelina... op.cit. pp. 58-59. 
tura en la Real Academia de Bellas Artes de San Fernando en $1830^{55}$. Como alumno en el estudio particular del vicesecretario de la Academia, Juan Miguel de Inclán Valdés, preparó las pruebas para superar el examen para maestro arquitecto presentándose a ellas el 20 de febrero de 1831. Presentó como prueba de pensado un proyecto de Iglesia Colegiata para una ciudad capital que en todos sus detalles se atiene a los modelos del más estricto neoclasicismo ${ }^{56}$. El Museo de la Academia conserva un diseño firmado por Daura el 17 de marzo de 1831 de "Casa de Campo para un matrimonio de comodidades" que está registrado como prueba de repente para maestro arquitecto, que muestra una distribución rigurosa de los volúmenes y ausencia de ornamentación ${ }^{57}$. El capitán de Infantería D. Juan Daura natural de Pla en Cataluña y edad de 45 años aparece aprobado el 24 de abril de $1831^{58}$. La promoción a Académico de Mérito debió ser casi inmediata porque la documentación nos informa de que Juan Daura, capitán de Infantería, fue creado Académico de Mérito el 27 de noviembre de $1831^{59}$.

La Academia siguiendo el programa establecido para alcanzar la condición de académico de mérito encargó a Daura la demostración en diseño de la planta y elevación por sección del patio de San Felipe el Real de Madrid mientras que el discurso consistiría en "Describir las diferentes formas que se conocen de calles en las grandes poblaciones, las ventajas e inconvenientes que presenta cada una de ellas , cuáles serán las que ofrecen más comodidades y hermosura a sus edificios, y qué situación se podrá elegir para formar una ciudad populosa" $^{\prime 60}$. Cinco arquitectos más dedicaron su discurso a este tema, un detalle muy revelador porque todos ocuparían con posterioridad puestos relevantes como maestros mayores de ciudades como Sevilla o Valladolid ${ }^{61}$.

55 CIRICI NARVÁEZ, Juan Ramón. El arquitecto Juan Daura, héroe de la Guerra de la Independencia. RAMOS SANTANA, A., ROMERO FERRER, A. (Eds): Cambio político y cultural en la España de entre siglos. Cádiz: Universidad de Cádiz, 2008. p. 438. Es la última aportación del autor al análisis de la obra de Daura.

56 CIRICI NARVÁEZ, Juan Ramón. Idem. p.438. El autor cita la documentación depositada en el archivo de la Real Academia de San Fernando: Expediente Juan Daura, Arquitectos 1831, Documentos Arquitectura leg. 2-9/5.

57 ARABASF: Museo: Planta y alzado de la fachada principal y sección AB. Casa de Campo o recreo para un matrimonio de comodidades. 1831, Registro A-1772. Prueba de repente para maestro arquitecto. Firmado el capitán Juan Daura. Escala gráfica de 190 pies castellanos. Técnica papel verjurado agarbanzado claro, tinta y aguada gris y rosa. En el reverso, escrito a tinta en el ángulo inferior derecho "aprobado en junta ordinaria de 24 de abril de 1831 de maestro arquitecto".

58 ARABASF: Leg. 3/154. Registro de Arquitectos Aprobados, libro $2^{\circ}$, folio 13vta.

59 ARABASF: Libro de Académicos de Mérito (1753-1845), leg. 3/18.

60 ARABASF: Discurso de Ingreso como Académico de Mérito por la arquitectura. Juan Daura, 1831. Leg. 3-311-1.

61 ANTIGÜEDAD DEL CASTILLO-OLIVARES, María Dolores. Teoría Urbana en la España de la primera mitad del siglo XIX. VV.AA. Homenaje al profesor Hernández Perera. Departamento de Historia del Arte II. Facultad de Geografía e Historia, Universidad Complutense. Ed. Dirección General de Patrimonio Histórico, Gobierno de Canarias, 1992, Pp.23 -33. Se analizan seis discursos redactados entre 1829 y 1843. 
Juan Daura: Casa de Campo para un matrimonio de comodidades. 1831. Academia San Fernando

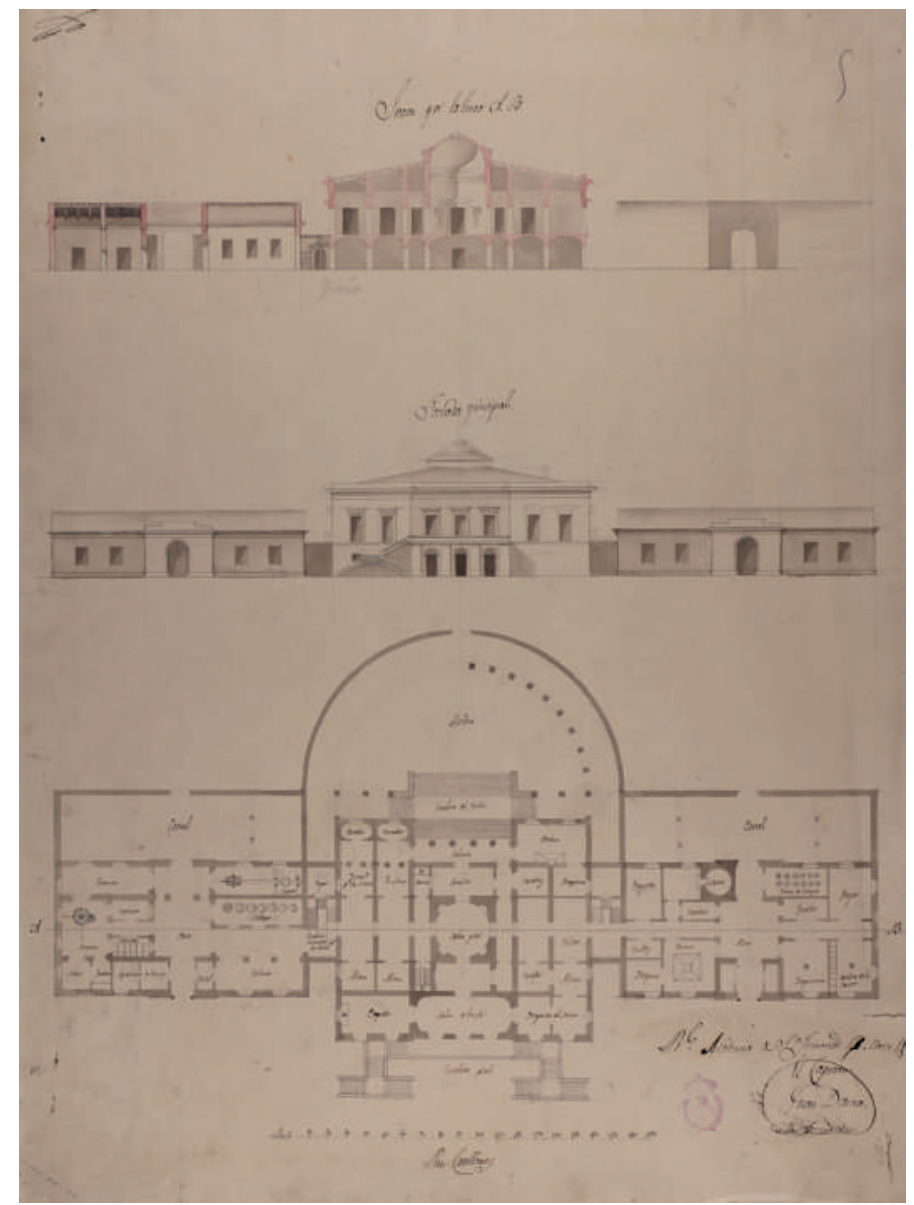

El discurso forzosamente erudito, está firmado y rubricado el 30 de agosto de 1831 y constata que Juan Daura antes de su llegada a Cádiz poseía un bagaje teórico y práctico suficiente para actuar sobre una ciudad en la que no sólo debería ocuparse de su embellecimiento con realizaciones concretas, sino de buscar el modelo de calle más perfecto, diseñar sus accesos, las entradas y las partes que unirán todas las demás. Todos los discursos de este tipo coinciden en situar fuera de la ciudad las dependencias o servicios necesarios que se considere deben estar ventilados, como hospitales, cementerios, cárceles, cuarteles o bien industrias que puedan producir malos olores o ruidos, asuntos que los teóricos del siglo XVIII tenían ya previstos y que en el siglo XIX se utilizó como medio para ensanchar la ciudad. Algunos de los párrafos del discurso resumen el ideario de un profesional maduro que afirma que "nosotros consideramos como digna de la prime- 
ra atención la salubridad, después la subsistencia, después la defensa y todo lo demás podemos mirarlo como accesorio". Sus referencias al estilo de construir es también una muestra de sentido práctico que enlaza con la arquitectura ecléctica: "Sabido el modo de construir moderno, sabiamente adaptado sin espíritu de escuela, tomando lo mejor que se hallase en la antigua, en la extranjera, y en la siempre preferible nuestra". Su párrafo final es una suma de intenciones y también una carta de presentación ante la sociedad en que deseaba trabajar: "Trazar las comunicaciones, aventurar las plazas, arrastrar las obras hidráulicas y cerrar y crear hasta las mayores capitales...el arquitecto que tenga como fruto de cuidadosa educación buenos principios de moral, natural despejo, noción expedita de los tres tratados principales de las matemáticas, grandes conocimientos en la delineación, montea, secciones y sombras, que reúna porción de modelos, que perciba y deduzca ideas generales y artísticas, consecuencias precisas y naturales, que conozca calidades, precios, ventajas, de materiales en el país donde obrase, que aproveche incesantemente las luces que como un torrente invasor se difunde de dos siglos a esta parte por la Europa...".

Daura asumió la conclusión de la Cárcel Real en 1836, siguiendo la labor de Torcuato Benjumeda, ya anciano y achacoso y al que sucederá también como arquitecto mayor de Cádiz. El desdichado edificio de la Cárcel Real ha quedado como una fachada monumental ya que su trasera, batida por el mar y los vientos, se cerró con materiales de escasa calidad que no han soportado bien el paso del tiempo ${ }^{62}$.

Uno de los primeros ejemplos de colaboración con Benjumeda fue el ensanche industrial de Campo de Guía en el Puerto de Santa María, uno de los pocos ejemplos de urbanismo neoclásico que conocemos. Como ya escribimos, el proyecto de Campo de Guía que firmaron Benjumeda y Daura en 1835 es la perfecta adecuación de los valores del urbanismo académicos a las necesidades de la población ${ }^{63}$. La Academia de San Fernando en la Junta de la sección de arquitectura del 26 de mayo de 1835 dio el visto bueno al proyecto de ampliación y acrecentamiento de El Puerto de Santa María cuyo plano topográfico y diseño de manzanas se había encomendado a los Académicos de Mérito Benjumeda y Daura, maestros mayores de la ciudad de Cádiz ${ }^{64}$.

62 CIRICI NARVÁEZ, Juan Ramón...El arquitecto Juan Daura...op.cit. p.439.

63 ANTIGÜEDAD, María Dolores. La necesidad de preservar los trazados urbanos: el caso de Campo de Guía (E1 Puerto de Santa María). GARCÍA PAZOS, Mercedes, CIRICI NARVÁEZ, Juan Ramón. (Eds.): Las tribulaciones en la tutela del patrimonio paisajístico y urbano. Actas de los encuentros de Primavera de la Universidad de Cádiz, 2001, p.152.

64 ARABASF: Actas de la Sección de Arquitectura, años 1832 a 1840. Acta de 26 de mayo de 1835. Leg. 3-142. 


\section{Figura 7}

\section{Benjumeda y Daura: Plano topográfico de los terrenos de Campo de Guía.} 1835. Archivo Histórico Municipal del Puerto de Santa María

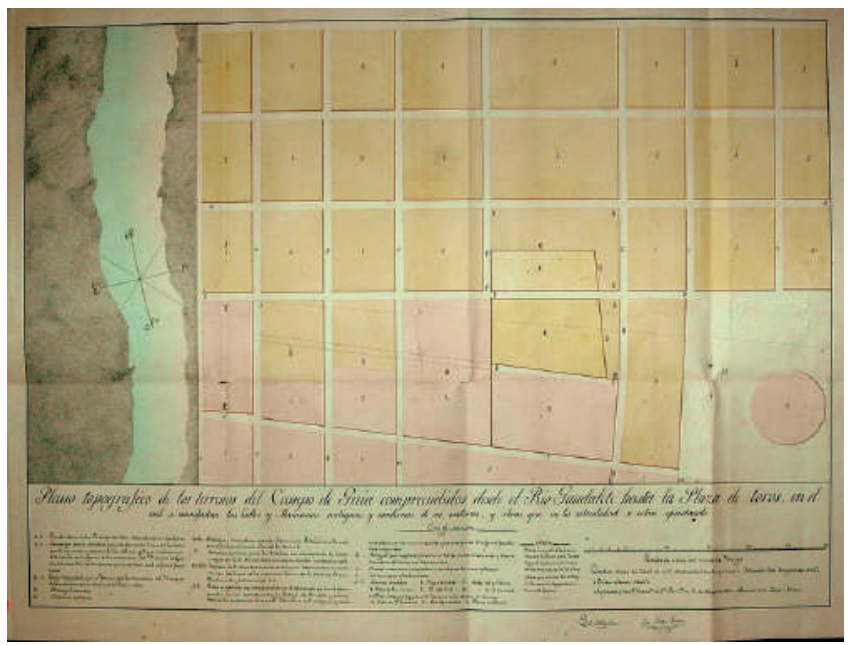

La Academia arbitraba aquí sobre la necesidad de proyectar un ensanche industrial donde pudiera establecerse la industria bodeguera. Demostró la potestad de la Academia para intervenir sobre cuestiones urbanísticas cuando la obra fuera iniciada por alguien que no estaba habilitado como maestro arquitecto o académico de mérito. Aunque el ensanche estaba destinado a fines industriales, contemplaba la ampliación de la población hacia el sureste y el noreste con una serie de manzanas regulares en cuadrícula ${ }^{65}$. También el plan recomendaba formar una plaza en la periferia de la Plaza de Toros para desahogo y la reserva de dos manzanas contiguas a la ribera del Guadalete para el comercio ${ }^{66}$.

Parte de la herencia de Benjumeda fue la continuación de la obra de la Catedral nueva gaditana por donde ya habían pasado varios arquitectos laureados y que aún estaba necesitada de una cúpula que cubriese el crucero sobre las pechinas construidas por Benjumeda. Sin la majestuosidad que pretendió darle Machuca, Daura logró erigir una cúpula que vo-

65 Plano topográfico de los terrenos del Campo de Guía comprendido desde el Rio Guadalete hasta la plaza de toros, cual se manifiestan las calles $\gamma$ manzanas antiguas y modernas de su entorno $\gamma$ obras $\gamma$ obras que en la actualidad se están ejecutando. Cádiz 11 de Abril de 1835, Torcuato José Benjumeda Acd. Y Juan Daura Acd. Archivo Histórico Municipal de El Puerto de Santa María, Policia Urbana, Obras, n1 2.

66 Campo de Guía ha sido objeto de varios estudios: SÁNCHEZ GONZÁLEZ, Rafael. Introducción al estudio del urbanismo portuense: El ensanche del Campo de Guía (1828-1838). Cádiz, Ed. Caja de Ahorros de Cádiz, 1986. serie Arte, n ${ }^{\circ}$. BARROS CANEDA, José Ramón. Arquitectura y urbanismo en El Puerto de Santa María durante el siglo XIX, 1995. P. 149 y ss. Tesis Doctoral, Sevilla. Disponible en línea: Q_Tesis_BAR_arq.pdf. También CIRICI NARVÁEZ, Juan Ramón. La arquitectura y otros aspectos artísticos del mundo de las bodegas. RAMOS SANTANA, A. y MALDONADO ROSSO, J. (Eds.): Vinos, vinagres, aguardientes y licores de la provincia de Cádiz. Diputación de Cádiz, 1997 p. 134-135. 
ces críticas han tildada de "achaparrada" o sencillamente de "engendro" ${ }^{67}$ que sin embargo demostró que Daura tenía sentido práctico y economía en el empleo de materiales. El proyecto fue presentado a la Academia el 1 de julio de $1832^{68}$.

También siguiendo los diseños de Benjumeda, Daura construyó el mercado de abastos que estuvo listo en 1837 aprovechando los terrenos de la huerta de los Franciscanos Descalzos enajenados por las medidas desamortizadoras decretadas durante el Trienio Constitucional (1820-1823), medidas que se verían incrementadas desde 1834 gracias a las políticas de Álvarez Mendizábal. Su arquitectura de recuerdo clásico muestra ya, sin embargo, un sentimiento romántico con el empleo libre de los órdenes clásicos.

Las medidas desamortizadoras son también el origen de la Plaza Mina resultante del espacio conseguido a expensa de la huerta del convento de San Francisco que Daura convierte en enclave ajardinado para desahogo del vecindario, uno más de los espacios liberados en el colmatado callejero de Cádiz ${ }^{69}$.

Son muchas las realizaciones de Daura que contribuyeron al embellecimiento y saneamiento de Cádiz en momentos de gran precariedad económica que demostraron su capacidad profesional para actuar en el medio urbano cuando un desgraciado incidente truncó su carrera de éxitos: el derrumbe en 1841 de la recién construida Plaza de Toros de Cádiz ${ }^{70}$. Una coincidencia desgraciada: el derrumbe de la Plaza de Toros de Cádiz en 1820 había hundido la reputación de Torcuato Benjumeda y fue también el inicio de su ocaso.

En 1841 un personaje singular irrumpió en la arquitectura gaditana: Juan de la Vega y Correa (1806-1883) que hasta el momento de su muerte ocupará los más elevados puestos en el escenario gaditano desde arquitecto mayor de la ciudad a director de arquitectura de la Academia de Nobles Artes para terminar como arquitecto provincial. Con él termina el Neoclasicismo institucional y echa a andar el rico, colorista e historicista eclecticismo isabelino ${ }^{71}$. De la Vega fue titulado Maestro arquitecto por la Real Academia de Bellas Artes de San Fer-

67 VV.AA. Guía de Arquitectura de Cádiz, 1995. P. 134-135. Se recoge una cuidada cronología sobre las etapas en la construcción de la catedral nueva. También CIRICI NARVÁEZ, Juan Ramón. El arquitecto Juan Daura... op.cit. p. 441.

68 ARABASF: Actas de la Sección de Arquitectura, años 1832 a 1840. Acta de la Junta de 27 de junio de 1832. Leg. 3-142. 69 CIRICI NARVÁEZ, Juan Ramón. El arquitecto Juan Daura...op. cit. p. 439.

70 CIRICI NARVÁEZ, Juan Ramón. El arquitecto Don Juan Daura y la Plaza de Toros de Cádiz de 1814. Cádiz, Gades, 1980. No 5, p.175-186.

71 CIRICI NARVÉZ, Juan Ramón. Juan de la Vega y la arquitectura gaditana del siglo XIX. Cádiz, 1992. Colegio oficial de Arquitectos de Andalucía Occidental. CIRICI NARVÁEZ, Juan Ramón. Reforma y acondicionamiento del Palacio de la Aduana en 1862: el Salón Regio. ANTIGÚEDAD, M.D., CIRICI, J.R. (Coord. Y Ed): Arquitectura y ciudad en España de 1845 a 1898. Ed Universidad de Cádiz y UNED, 2001, Pp. 205-207. 
nando el 7 de agosto de $1836^{72}$ presentando como prueba de pensado "Planta y alzado de una bolsa y tribunal de comercio" ${ }^{73}$ una tipología representativa de la ciudad burguesa.

\section{Figura 8}

\section{Juan de la Vega: Bolsa y tribunal de comercio. 1836. Academia de San Fernando}

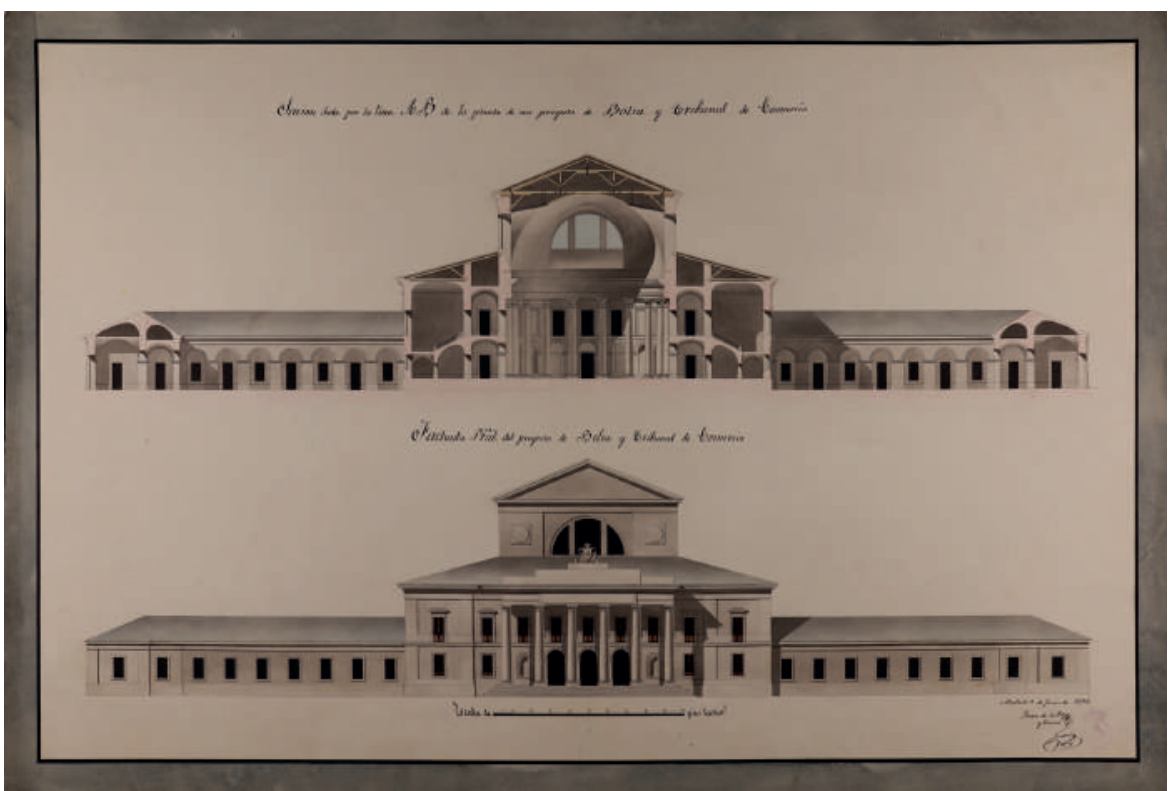

El título de Académico de Mérito le fue concedido por la Academia Gaditana en 1843, nunca fue lo fue por San Fernando. Su huella profunda se dejó sentir en toda la ciudad donde su creatividad y sentido artístico contribuyeron en buena medida a formar la imagen de la ciudad que hoy conocemos.

72 ARABASF: Acta de la junta ordinaria de 7 de agosto de 1836. Libro de Actas 1832-1840. Sig. 3-142.

73 ARABASF: Museo, prueba de pensado para maestro arquitecto, Madrid, 3 de junio de 1836. Planta y alzados sig. A-1269, A-1270, A-1271, A-1272. 